Sprangers, M.A.G., Regt, E.B. de, Andries, F., Agt, H.M.E. van, Bijl, R.V., Boer, J.B. de,

Foets, M., Hoeymans, N., Jacobs, A.E., Kempen, G.I.J.M., Miedema, H.S., Tijhuis,

M.A.R., Haes, H.C.J.M. de

Which chronic conditions are associated with better or poorer quality of life?

Journal of Clinical Epidemiology: 53, 2000, nr. 9, p. p. 895-907

\begin{tabular}{|l|l|}
\hline Postprint Version & 1.0 \\
Journal website & $\underline{\text { http://dx.doi.org }}$ \\
\hline Pubmed link & $\begin{array}{l}\text { http://www.ncbi.nlm.nih.gov/entrez/query.fcgi?cmd=Retrieve\&db=pubmed\&dop } \\
\text { t=Abstract\&list uids=11438406\&query_hl=16\&itool=pubmed_docsum }\end{array}$ \\
\hline DOI & \begin{tabular}{l} 
10.1016/S0895-4356(00)00363-2 \\
\hline
\end{tabular}
\end{tabular}

\title{
Which chronic conditions are associated with better or poorer quality of life?
}

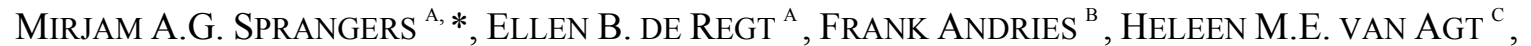
RoB V. BIJL ${ }^{\mathrm{D}}$, JOSIEN B. DE BOER ${ }^{\mathrm{E}}$, MARLEEN FoETS ${ }^{\mathrm{F}}$, NANCY HOEYMANS ${ }^{\mathrm{G}}$, ANNELIES E. JACOBS ${ }^{\mathrm{H}}$ , GERTRUdis I.J.M. KEMPEN ${ }^{\mathrm{I}}$, HAROLD S. MiEdEMA ${ }^{\mathrm{J}}$, MARJA A.R. TIJHUIS ${ }^{\mathrm{G}}$, HANNEKE C.J.M. DE HAES $^{\text {A }}$

${ }^{a}$ Department of Medical Psychology, Academic Medical Center, University of Amsterdam, Meibergdreef 15, 1105 AZ Amsterdam, The Netherlands

${ }^{\mathrm{b}}$ NIA TNO, Leiden, The Netherlands

${ }^{c}$ Instituut Maatschappelijke Gezondheidszorg, Erasmus University, Rotterdam, The Netherlands

${ }^{\mathrm{d}}$ Netherlands Institute of Mental Health and Addiction, Utrecht, The Netherlands

e Department of Medical Psychology and Psychotherapy, Erasmus University, Rotterdam, The Netherlands

${ }^{f}$ Netherlands Institute of Primary Health Care (NIVEL), Utrecht, The Netherlands

${ }^{9}$ National Institute of Public Health and the Environment, Bilthoven, The Netherlands

${ }^{h}$ Centre for Quality of Care Research (WOK), University of Nijmegen, Nijmegen, The Netherlands

' Northern Center for Healthcare Research, Groningen and Department of Medical Sociology, Maastricht University, Maastricht, The Netherlands

i TNO Prevention and Health, Leiden, The Netherlands

* Corresponding author. Tel: 31-20-566-4661; fax: 31-20-566-9104. E-mail address : m.a.sprangers@amc.uva.nl (M.A.G. Sprangers)

\begin{abstract}
The objective of the present study is to compare the QL of a wide range of chronic disease patients. Secondary analysis of eight existing data sets, including over 15,000 patients, was performed. The studies were conducted between 1993 and 1996 and included population-based samples, referred samples, consecutive samples, and/or consecutive samples. The SF-36 or SF-24 were employed as generic QL instruments. Patients who were older, female, had a low level of education, were not living with a partner, and had at least one comorbid condition, in general, reported the poorest level of QL. On the basis of rank ordering across the QL dimensions, three broad categories could be distinguished. Urogenital conditions, hearing impairments, psychiatric disorders, and dermatologic conditions were found to result in relatively favorable functioning. A group of disease clusters assuming an intermediate position encompassed cardiovascular conditions, cancer, endocrinologic conditions, visual impairments, and chronic respiratory diseases. Gastrointestinal conditions, cerebrovascular/neurologic conditions, renal diseases, and musculoskeletal conditions led to the most adverse sequelae. This categorization reflects the combined result of the diseases and comorbid conditions. If these results are replicated and validated in future studies, they can be considered in addition to information on the prevalence of the diseases, potential benefits of care, and current disease-specific
\end{abstract}


Sprangers, M.A.G., Regt, E.B. de, Andries, F., Agt, H.M.E. van, Bijl, R.V., Boer, J.B. de,

Foets, M., Hoeymans, N., Jacobs, A.E., Kempen, G.I.J.M., Miedema, H.S., Tijhuis,

M.A.R., Haes, H.C.J.M. de

Which chronic conditions are associated with better or poorer quality of life?

Journal of Clinical Epidemiology: 53, 2000, nr. 9, p. p. 895-907

expenditures. This combined information will help to better plan and allocate resources for research, training, and health care.

\section{INTRODUCTION}

The past decades have witnessed an increasing prevalence of chronic disorders, as a result of better prevention, management of infectious diseases, improved living conditions, medical technological improvements, and the overall aging of the population. The health-related quality of life (QL) of patients with chronic disorders is frequently impaired. An important objective of health care in the U.S. and other Western countries is to increase the span of life years while maintaining an optimal QL $[1,2]$. QL is not only a primary concern of patients, their families, and clinicians, but is also of policy interest. Estimates of the relative impact of chronic diseases on QL are needed to better plan and allocate resources for research, training, and health care.

While numerous studies have addressed the impact of chronic diseases and their treatment on QL, the relative impact of different chronic conditions on patients' level of subjective functioning is mostly unknown $[3,4]$. On the basis of a systematic literature review, ${ }^{1}$ we identified only 20 studies [3-22] that compared the QL across chronic disease populations. The question arises what these studies reveal about the relative position of the conditions regarding QL. To enable a comparison across conditions, they were aggregated into disease clusters. For example, hypertension and myocardial infarction have been grouped into a cluster labeled "cardiovascular conditions" (Fig. 1). These disease clusters were then compared within each study. These comparisons resulted in a positive, an equivalent, or a negative position of each disease cluster relative to other disease clusters with respect to physical/functional and/or psychosocial well-being. The relative position of each disease cluster was then established across studies (Table 1).

\section{[ FIGURE 1 ]}

\section{[ TABLE 1 ]}

Both musculoskeletal and renal disease were found to result in greater physical and functional impairments, while the psychosocial sequelae were modest. The remaining chronic conditions appear to have a comparable impact on both physical/ functional and psychological/social aspects of wellbeing. Hearing or visual impairments, gastrointestinal diseases, and endocrinologic conditions appear to hold a predominantly positive position relative to other diseases. A broad group encompassing chronic respiratory diseases, cancer, urogenital conditions, cardiovascular conditions, musculoskeletal conditions, and renal diseases was found to have both a positive and negative position relative to other conditions. Finally, the disease clusters that were found to hold mainly a negative position include AIDS, cerebrovascular/neurologic conditions, and psychiatric disorders. Clearly, given the underrepresentation of a number of disease clusters (e.g., hearing impairments and renal disease), the heterogeneity of the studies with respect to sample composition, sample size, instruments and

\footnotetext{
${ }^{1}$ A series of literature searches was conducted on MEDLINE and CLINPSYCH databases for the years 1992-1998, to identify studies that compared the QL across chronic disease populations. The medical subject headings "quality of life" and its equivalents (i.e., "well-being," "health status," "physical, psychological or social functioning") were combined with "chronic disease." Additionally, searches were performed on the basis of the combinations "psychological adaptation," "psychological distress," "social support," "social adjustment," "activities of daily living" on the one hand and "chronic disease" on the other. Additional searches were conducted via the references lists of the selected articles. Studies published in English and Dutch were included in the review. Studies were selected for review in which: a) at least two different chronic diseases were compared; b) at least one of the four QL dimensions was examined (i.e., physical, functional, psychological, or social wellbeing); and c) the levels (means) of these dimensions were compared and/or tested across the chronic disease populations. Studies were excluded from this review that were concerned with pediatric subjects (i.e., children, adolescents), because the problems involved in pediatric health care are substantially different from those encountered with adult patients. The search identified 20 studies that met these criteria. Because the research in this area is multidisciplinary, it is difficult to know if one has collated an exhaustive list of references. Nevertheless, given the identified approach, we are confident that the studies included provide a representative picture of the current research in this area. The literature study is documented in: Haes de JCJM, Sprangers MAG, Regt de HB et al. Adaptieve Opgaven Bij Chronische Ziekte. Nederlandse Organisatie voor Wetenschappelijk Onderzoek, Den Haag, 1997.
} 
Sprangers, M.A.G., Regt, E.B. de, Andries, F., Agt, H.M.E. van, Bijl, R.V., Boer, J.B. de,

Foets, M., Hoeymans, N., Jacobs, A.E., Kempen, G.I.J.M., Miedema, H.S., Tijhuis,

M.A.R., Haes, H.C.J.M. de

Which chronic conditions are associated with better or poorer quality of life?

Journal of Clinical Epidemiology: 53, 2000, nr. 9, p. p. 895-907

procedures, and the methodological limitations inherent in such comparisons, these results need to be viewed with caution.

Empirical data are needed to corroborate these findings. We therefore investigated the level and profiles of QL in a wide range of chronic disease populations in response to a request of the Netherlands Committee of Chronic Diseases. This committee wished to gain insight into the relative impact of chronic diseases on QL, which could help to better allocate research funds. A secondary analysis on eight existing data sets was conducted. The research questions were threefold and pertained to the extent to which: a) sociodemographic characteristics and comorbidity affect QL across chronic disease patients, b) disease categories within their respective disease clusters differ in the level and pattern of QL, and c) the disease clusters themselves differ in the level and pattern of QL. The terms QL, well-being, health status, and functioning will be used interchangeably.

\section{METHODS}

\subsection{Selection of data sets}

To identify relevant data, all research groups known to examine chronic diseases in the Netherlands were mailed a questionnaire asking detailed information about available data sets that could be used for secondary analysis. Thirty-two potentially relevant data sets were thus identified. The following guidelines were used to select studies: 1) full coverage of QL domains (i.e., physical, functional, psychological, and social well-being) [23,24]; 2) use of standardized QL instruments; 3) inclusion of a range of chronic diseases; 4) large overall sample size (preferably more than 200); 5) medically confirmed diagnoses (in contrast to self-report); 6) recency of data (since 1992); and 7) breadth of accrual in terms of geographical regions. While these criteria were not always fulfilled (e.g., diagnoses were frequently based on selfreport), the use of a similar, standardized QL instrument was employed as the most important criterion, given the study objective. Eight data sets were thus selected. The remaining 24 data sets employed a different questionnaire, included only one or two disease categories, and/or were based on small samples accrued in restricted geographical regions. A detailed description of the selected data sets is provided in the Appendix.

\subsection{Levels of aggregation}

These eight data sets provided information of 47 patient samples and over 15,000 patients (see Appendix). Two levels of aggregation were distinguished. First, patient samples were combined when they belonged to the same disease category (e.g., hypertension in datasets 5 and 8). Second, the disease categories were combined to form disease clusters (e.g., hypertension and heart condition were grouped into a cluster labeled cardiovascular conditions). In some cases, all the individual patient samples could be combined into one cluster (e.g., chronic respiratory diseases), or the cluster consisted of only one patient sample (e.g., hearing impairments) (Fig. 1).

\subsection{Provided data}

\subsubsection{Dependent measures}

The MOS 36-Item Short-Form Health Survey (SF-36) has been used in seven studies. The SF-36 is a generic health status instrument designed for use across a wide range of chronic disease populations. The SF-36 has been shown to have excellent reliability and validity when employed with diverse patient populations in the U.S. [25,26] and the Netherlands [27,28].

The SF-36 is composed of 36 items, organized into 8 multi-item scales covering a similar number of dimensions, including physical functioning (PF), physical role functioning (PRF), bodily pain (BP), general health $(\mathrm{GH})$, vitality $(\mathrm{V})$, social functioning $(\mathrm{SF})$, emotional role functioning (ERF), and mental health $(\mathrm{MH})$. These dimensions are ordered from first to last according to the extent to which they measure physical or mental functioning [29]. One additional item pertains to health transition (HT). On the basis of these separate subscales, component summary scores were calculated to provide a global measure of physical (PCS) and mental functioning (MCS), respectively. These summary scores were calculated according to guidelines provided by the director of the International Quality of Life Assessment project (Barbara Gandek, New England Medical Center, personal communication, 
Sprangers, M.A.G., Regt, E.B. de, Andries, F., Agt, H.M.E. van, Bijl, R.V., Boer, J.B. de,

Foets, M., Hoeymans, N., Jacobs, A.E., Kempen, G.I.J.M., Miedema, H.S., Tijhuis,

M.A.R., Haes, H.C.J.M. de

Which chronic conditions are associated with better or poorer quality of life?

Journal of Clinical Epidemiology: 53, 2000, nr. 9, p. p. 895-907

1998). The means and standard deviations of the general population of Amsterdam were used to transform the raw subscale scores to $\mathrm{Z}$-scores. These $\mathrm{Z}$-scores were multiplied with the weights of the American general population because the weights of the Dutch general population were not available at the time. ${ }^{2}$ These scores were subsequently multiplied by 10 and summed with 50 to obtain transformed summary scores that are normally distributed with a mean of 50 and a standard deviation of 10. The scales, single item, and summary scores range from 0 to 100 , with higher scores indicating a better health status. Means and standard deviations were provided by the original researchers for each subscale, the single item, and the two summary scores.

In one large data set (the GLAS study), the MOS Short- Form General Health Survey (SF-20) [30] has been used, supplemented by the four items of the vitality scale as used in the SF-36, resulting in the SF-24. Because both instruments originate from the Rand Health Insurance Study Questionnaire, the two questionnaires are comparable in content, albeit not entirely identical with respect to the wording of some of the items and response options. With the exception of the subscale "emotional role functioning" and single item "health transition," the SF-24 encompasses the same dimensions as the SF-36. The Dutch version of the questionnaire has established levels of reliability and validity [31]. Summary scores for the SF-24 cannot be calculated.

\subsubsection{Sociodemographic characteristics and comorbidity}

The variables included: age ( $<45$ years; $45-64$ years; $>64$ years); gender, education level (low, intermediate, high); living situation (married or living together vs. other); and comorbidity (at least one comorbid condition vs. none). Per background characteristic, means and standard deviations were provided for each patient sample for the subscales of the SF-36/SF-24, and the single item and the two summary scores of the SF-36.

\subsection{Analysis}

\subsubsection{Influence of sociodemographic characteristics and comorbidity}

First, the potential influence of the sociodemographic characteristics and comorbidity was examined for each patient sample separately. Clear, unequivocal guidelines for interpreting differences between mean scores as clinically and socially relevant are not available yet [29,32]. However, Ware [29] considers a difference of 2 points on a scale from 0 to 100 as "very small" (p. 7:9). We therefore decided that mean scores that differed less than 2 points were equivalent. This criterion was employed for the mean subscale scores and the mean summary scores. Subsample sizes less than 10 patients were ignored.

Second, the extent to which a difference between subgroups pointed systematically in one direction (e.g., a systematically higher score for women than for men) was established for each patient sample. The following decision rules were employed. A difference between two means (e.g., males vs. females) for the dimensions was considered to be systematic if: a) at least six of nine dimensions pointed into one direction, while the remaining three dimensions were equivalent; or b) at least seven of nine dimensions pointed into one direction, while only one remaining dimension showed a difference in the opposite direction. All other cases were considered indicative of the absence of a systematic effect of a particular background characteristic. In case of seven dimensions (for the SF-24) and/or three categories (i.e., for age and education) comparable decision rules were employed. Third, the number of times a background characteristic was found to exert a systematic effect was calculated across patient samples.

\subsubsection{Comparison of disease categories within their respective disease clusters}

For those disease categories that encompassed more than one patient sample (Fig. 1), overall means were calculated by averaging the means of the constituent samples, weighted by sample size. With

\footnotetext{
${ }^{2}$ Ware et al. [36] have compared PCS and MCS scores using standard U.S. scoring algorithms with factor weights derived from the U.S. general population, with those using country-specific factor weights. The correlations between the two SF-36 summary measures using standard U.S. and country-specific scoring algorithms were 0.991 and 0.990 , respectively, for a Dutch sample. The strength of these findings led the authors to recommend the use of U.S.-derived scoring algorithms.
} 
Sprangers, M.A.G., Regt, E.B. de, Andries, F., Agt, H.M.E. van, Bijl, R.V., Boer, J.B. de,

Foets, M., Hoeymans, N., Jacobs, A.E., Kempen, G.I.J.M., Miedema, H.S., Tijhuis,

M.A.R., Haes, H.C.J.M. de

Which chronic conditions are associated with better or poorer quality of life?

Journal of Clinical Epidemiology: 53, 2000, nr. 9, p. p. 895-907

respect to specific QL dimensions, a difference of less than 1 point between mean scores was considered equivalent. This difference is smaller than the 2-point difference employed for individual samples (see former paragraph), because the variance of aggregated means is smaller than the variance of their component means. For each dimension, the mean scores were ranked across the disease categories within the disease cluster. Ties (cases where differences in mean scores were less than 1 point) were given a mean ranking. The rankings were subsequently summed for each disease category across the dimensions. To enable comparison across studies, only the seven scales used by both the SF-36 and SF-24 were used. The summed ranking score is minimally seven (the number of subscales) and maximally seven times the number of disease categories compared. A lower ranking sum is indicative of better functioning. Because the two summary scores were missing in a number of data sets, these were not taken into account.

\subsubsection{Comparison across disease clusters}

Mean scores were calculated per disease cluster for each separate dimension and for the physical and mental component summary scores. If the cluster consisted of the original patient samples, a weighted mean score was calculated. If the disease cluster consisted of disease categories (Fig. 1), the mean score was based on the means of these disease categories. ${ }^{3}$ The means were subsequently ranked per QL dimension across the disease clusters. A rank score of 1 indicated the most favorable health status and a ranking of 13 indicated the poorest level of functioning, given the number of disease clusters. Mean rank scores were given to ties (a difference of less than 1 point). The rank scores for the seven dimensions were subsequently summed per disease cluster to obtain an overall rank order of the disease clusters.

\section{RESULTS}

\subsection{Influence of sociodemographic characteristics and comorbidity}

\subsubsection{Age}

Older patients reported a poor QL than younger ones on the QL dimensions and physical functioning. None of the comparisons revealed results that were in the opposite direction. There was no effect of age on mental functioning (Table 2).

\section{[ TABLE 2 ]}

\subsubsection{Gender}

Male patients reported a more positive or comparable level of QL than female patients on the separate QL dimensions and mental functioning. No such gender effect was found for physical functioning.

\subsubsection{Education}

In general, a low level of education coincided with poor QL as indicated by the results of the separate dimensions and physical functioning. This effect was less clear for mental functioning. No differences were found for the QL dimensions, physical and mental functioning between an intermediate or high level of education (data not shown).

\subsubsection{Living situation}

\footnotetext{
${ }^{3}$ Because these means were not further corrected for sample size, we examined whether the ranking differed when it was based on weighted means. While these different approaches resulted in a slightly different rank order, the general distinction among disease clusters was not affected.
} 
Sprangers, M.A.G., Regt, E.B. de, Andries, F., Agt, H.M.E. van, Bijl, R.V., Boer, J.B. de,

Foets, M., Hoeymans, N., Jacobs, A.E., Kempen, G.I.J.M., Miedema, H.S., Tijhuis,

M.A.R., Haes, H.C.J.M. de

Which chronic conditions are associated with better or poorer quality of life?

Journal of Clinical Epidemiology: 53, 2000, nr. 9, p. p. 895-907

Patients who live with a partner reported a better QL than patients who have a different living situation on the specific dimensions and mental functioning. This effect was not reflected in physical functioning.

\subsubsection{Comorbidity}

Patients with at least one comorbid condition reported a poorer QL on the separate dimensions, the physical and mental functioning. The results never pointed in the opposite direction.

\subsection{Comparison of disease categories within their respective disease clusters}

\subsubsection{Cardiovascular conditions}

Patients with hypertension reported better functioning than patients with a heart condition on all dimensions, with the exception of mental health (Table 3).

\section{[ TABLE 3 ]}

\subsubsection{Cerebrovascular/neurologic conditions}

The following rank order was obtained (from best to poorest QL): 1) neuromuscular disease; 2) migraine; 3 ) stroke; 4) multiple sclerosis; and 5) Parkinson/epilepsy. Patients with neuromuscular disease and migraine clearly reported the most favorable levels of functioning. However, patients with migraine had a different score pattern than the remaining patient groups. While they reported better physical and role functioning, general health, and vitality, they reported the highest level of pain. While multiple sclerosis patients and patients with neuromuscular disease reported the lowest level of pain, the health status of patients with multiple sclerosis, Parkinson's disease, or epilepsy was most severely impaired.

\subsubsection{Endocrinologic conditions}

While the summed rank scores were comparable, they were more favorable for patients with thyroid gland impairments than for those with diabetes. The largest differences between these disease categories were found for role functioning, general health, and social functioning.

\subsubsection{Gastrointestinal conditions}

Patients with an ulcer in the stomach or duodenum or with bowel disease had systematically higher levels of physical, role, and social functioning than patients with liver disease, gall stones, or gall bladder inflammation. However, the mean scores of the remaining dimensions were comparable across the two disease categories.

\subsubsection{Musculoskeletal conditions}

The ranking resulted in the following order: 1) rheumatoid arthritis; 2) back impairments; and 3) osteoarthritis/ other joint complaints. While patients with rheumatoid arthritis reported less pain, better social and mental functioning, they reported poorer role functioning, general health, and vitality.

\subsubsection{Psychiatric disorders}

Patients with alcohol abuse/dependence reported better functioning on all dimensions than patients with either anxiety disorders or depression. Patients with depression reported consistently the poorest level of functioning.

\subsection{Comparisons across disease clusters}

\subsubsection{Specific QL dimensions}


Sprangers, M.A.G., Regt, E.B. de, Andries, F., Agt, H.M.E. van, Bijl, R.V., Boer, J.B. de,

Foets, M., Hoeymans, N., Jacobs, A.E., Kempen, G.I.J.M., Miedema, H.S., Tijhuis,

M.A.R., Haes, H.C.J.M. de

Which chronic conditions are associated with better or poorer quality of life?

Journal of Clinical Epidemiology: 53, 2000, nr. 9, p. p. 895-907

Table 4 presents the rank order across the QL dimensions, with urogenital conditions having the best and musculoskeletal conditions the poorest QL. Three striking results merit attention. First, the health status profiles vary widely across disease clusters. For example, while patients with gastrointestinal conditions, cerebrovascular/neurologic conditions, renal disease, or musculoskeletal conditions reported the lowest levels of physical functioning and physical role functioning they differ in other respects. Patients with cerebrovascular/neurologic conditions reported relatively favorable levels of pain, but were found to have the poorest levels of social functioning and mental health. Patients with musculoskeletal conditions reported the poorest levels of physical functioning, role functioning and pain, while patients with renal disease reported the poorest level of general health. Second, the pattern of mean scores of psychiatric patients is entirely different from that of physically ill patients.

Psychiatric patients reported relatively poor levels of vitality and mental functioning, while the levels of physical and role functioning were highest in comparison to all other patient clusters. Third, the discrepancies in mean scores of the mental functioning subscales varies within narrower margins across the disease clusters than those of the physical functioning scales.

\section{[ TABLE 4 ]}

\subsubsection{Physical and mental health}

The available mean scores of the physical and mental component summary scores are depicted in Fig. 2. Because the means of these summary scores are set at 50 (see section on Dependent Measures), the figure can be divided into four quadrants. First, the most positive quadrant (physical and mental component summary scores $>50$ ) is empty, indicating that patients in all disease clusters were impaired with respect to at least one dimension. Second, while psychiatric patients reported the highest level of physical functioning $(>50)$, their mental functioning was poorest. Third, patients with cardiovascular conditions, hearing impairments, and musculoskeletal disease reported relatively positive levels of mental functioning $(>50)$, while their level of physical functioning was among the most negative. Fourth, the majority of disease clusters were found to have levels of physical as well as mental functioning below 50, including visual impairments, cerebrovascular and/or neurologic conditions, endocrinologic conditions, cancer, and chronic respiratory conditions.

\section{[ FIGURE 2 ]}

\section{CONCLUSIONS}

\subsection{Influence of sociodemographic characteristics and comorbidity}

The extent to which the sociodemographic characteristics and comorbidity exert a systematic effect on perceived QL was examined for each patient sample separately. Some clear trends emerged, despite the heterogeneity of the data sets. Patients who were older, female, had a low level of education, were not living with a partner, and had at least one comorbid condition, in general, reported the poorest level of QL.

\subsection{Comparisons of disease categories within their respective disease clusters}

Within disease clusters comparisons were made of component disease categories to examine the extent to which these disease categories differ in magnitude and type of impaired QL. Frequently, clear and interpretable patterns of functioning emerged as was the case with hypertension versus heart condition; thyroid gland impairments versus diabetes; ulcer in the stomach/duodenum versus liver disease/ gallstones; and alcohol abuse/dependence versus anxiety disorders and depression. The profiles of neuromuscular disease and migraine compared to stroke and to multiple sclerosis and Parkinson's disease/epilepsy were not entirely clear and straightforward. Additionally, the levels and profiles of functioning of rheumatoid arthritis versus back impairments versus osteoarthritis/other joint complaints were at odds with clinical expectations and may need to be viewed with some reserve. 
Sprangers, M.A.G., Regt, E.B. de, Andries, F., Agt, H.M.E. van, Bijl, R.V., Boer, J.B. de,

Foets, M., Hoeymans, N., Jacobs, A.E., Kempen, G.I.J.M., Miedema, H.S., Tijhuis,

M.A.R., Haes, H.C.J.M. de

Which chronic conditions are associated with better or poorer quality of life?

Journal of Clinical Epidemiology: 53, 2000, nr. 9, p. p. 895-907

\subsection{Comparisons across disease clusters}

Disease clusters were compared to examine the extent to which they differ in the level and pattern of reported QL. Behind the resulting rank order very different profiles of functioning were hidden as revealed by the score pattern of the different dimensions and of the physical and mental component summary scores. Some disease clusters, such as musculoskeletal conditions, were characterized by profound impairments. Others were typified by adverse psychosocial or mental functioning, as was the case with psychiatric conditions. Clearly, the majority of disease clusters were plagued by physical as well as mental dysfunctions.

The results of the extant literature are generally in line with those of the secondary analysis. Hearing impairments were found to result in relatively favorable functioning. A group of disease clusters assuming an intermediate position encompassed cardiovascular conditions, cancer, endocrinologic conditions, and chronic respiratory diseases. Patients who reported the poorest levels of functioning were those with cerebrovascular/neurologic conditions, renal disease, and musculoskeletal conditions. Discrepancies between the extant literature and the current study were found with respect to visual impairments and gastrointestinal disease, which assumed a less favorable position in the secondary data analysis than in the literature. Conversely, urogenital conditions and psychiatric disorders, in particular, had a more favorable position in the current data analysis in comparison to the extant literature.

Overall, the level of functioning of all disease clusters was lower than that of a healthy population, despite the strong variations across disease clusters. Three studies $[28,33,34]$ have provided the responses to the SF-36 or SF-24 of Dutch healthy individuals. A comparison with these QL results indicates that the discrepancies are substantial. Relatedly, the mean summary scores were occasionally more than half a standard deviation (5 points) below the mean of 50, thus revealing a difference of a moderate to large magnitude.

\section{DISCUSSION}

A number of conceptual and methodological constraints of the study merit attention. Conceptually, the choice of a generic health status instrument was needed, by definition, to enable comparison across different patient populations. However, this has inherent limitations regarding the domains of comparison. Moreover, such a generic instrument may not address those issues of relevance to particular patient groups, such as disease symptoms or treatment side effects. To the extent that such disease-specific aspects do not affect the generic domains, the resulting score is only a limited reflection of patients' health status.

Additionally, a number of issues may have compromised the representativeness of the data. First, a number of diseases within a disease cluster or disease clusters themselves may not be represented. For example, psychiatric patients with psychoses or schizophrenia and AIDS patients are not included. Second, a number of chronic conditions may have been underrepresented with respect to levels of severity (see Appendix). For example, some data sets excluded patients under the care of a specialist or with serious comorbidities. Additionally, an underrepresentation in the spectrum of severe levels of disease due to nonresponse may have occurred [35]. This nonresponse might have exerted a differential bias across conditions. For example, one could imagine that persons with mild levels of hearing and visual impairments are more inclined to complete written questionnaires than those who are more seriously afflicted. Conversely, persons with severe levels of dermatologic disorders or respiratory diseases are expected to be more motivated to complete a lengthy questionnaire than those with mild levels of disease. Third, in a number of data sets the selection of patients was limited with respect to sociodemographic characteristics (e.g., where inclusion criteria have been restricted to specific age ranges or to gender). Fourth, the representativeness may also have been affected adversely by limited sample size, as was the case with hearing impairments, renal disease, and visual impairments. Finally, the number of subsamples per condition varies considerably. Clearly, the larger the number of subsamples the more likely the combination of samples will provide a representative picture of the particular disease. Despite these limitations, the data are expected to provide a realistic representation of these chronic conditions in the Netherlands, given the diversity and magnitude of the eight data sets, the face validity of the results, and the concordance with results from the literature. 
Sprangers, M.A.G., Regt, E.B. de, Andries, F., Agt, H.M.E. van, Bijl, R.V., Boer, J.B. de,

Foets, M., Hoeymans, N., Jacobs, A.E., Kempen, G.I.J.M., Miedema, H.S., Tijhuis,

M.A.R., Haes, H.C.J.M. de

Which chronic conditions are associated with better or poorer quality of life?

Journal of Clinical Epidemiology: 53, 2000, nr. 9, p. p. 895-907

The influence of comorbidity on perceived QL is worthy of note. Patients with comorbid conditions in particular reported the poorest levels of physical and mental function. Given the age ranges of the subjects included in the analyses, a substantial percentage of subjects will have one or more comorbid conditions. For example, hypertension, heart condition, and diabetes mellitus have a likely high rate to concur. Additionally, renal failure may result from long-standing hypertension or diabetes mellitus. Moreover, in three data sets (3,5, and 8, see Appendix) individuals could have been classified in several disease categories. Because we were unable to separate systematically and uniformly the influence of the disease categories from concomitant conditions, the reported QL levels result from the combined effect of disease and comorbidity. Whereas this constraint limits the conclusions regarding the influence of disease categories, it pays credit to the disease burden experienced by patients diagnosed with these diseases.

The interpretation of the ranked differences also merits attention. There are no clear-cut ways of interpreting the clinical relevance of the observed differences [32]. While the adopted criterion of a difference of at least 2 points (or 1 point for aggregated means) is plausible, it is not empirically substantiated. Moreover, given the heterogeneity inherent to higher order clustering, the variability in the range of means is substantial. Relatedly, the combination of all data into one dataset would have allowed for statistical analysis, controlling for interactions among different factors, and would provide information regarding the statistical significance of the differences. However, because combining the data into one database was impossible, we have adopted a conservative, descriptive approach aimed at ranking the different disease categories and clusters, thus setting limits to the interpretation of the results.

While secondary data analysis makes use of a wealth of information that would otherwise be ignored, its limitations are profound as a result of which primary data collection is preferable. Studies in this area should ideally be characterized by the use of large overall samples that are representative of the full range of chronic diseases qua disease severity and relevant background characteristics. The diagnoses should be medically confirmed. Additionally, standardized QL instruments should be administered according to similar procedures. Statistical analysis should provide information regarding interactions among disease and sociodemographic characteristics and comorbidity. Finally, standardized differences between health status profiles need to be established.

In order to guarantee a fair and rational health care system, societal costs associated with research, training, and use of health services, need to be allocated according to the criteria a society adopts. Those areas need to be identified that are in greatest need according to those criteria and/or offer the greatest benefits in relation to their costs. In this context, the comparisons across the 13 disease clusters are worthy of note. If these results are replicated and validated in future studies, they can be considered in addition to information on the prevalence of the diseases, potential benefits of care, and current disease-specific expenditures. This combined information can serve a number of purposes. For example, health care service provision can be better planned. Distributive injustice where resource allocation is not empirically warranted can thus be diminished. Finally, as was the purpose of our study, research funds can be allocated to patient groups with those chronic diseases and/or sociodemographic characteristics who are in greatest need.

\section{ACKNOWLEDGMENTS}

The research reported in this article was supported by a grant from the Dutch Council for Medical and Health Research, research program "Chronic diseases," financed by the Ministry of Health, Wellbeing and Sports. We are indebted to the Committee Zorg, Opvang en Begeleiding for identifying existing data sets and to Dr. R.P.W. Heinsbroek for his advice throughout the project. We also thank Dr. P. Oosterveld and Dr. A. de Boer for comments during the data analysis and E. Verkooijen for data preparation and secretarial support. We finally would like to thank two anonymous reviewers for helpful comments.

\section{TABLES AND FIGURES}


Sprangers, M.A.G., Regt, E.B. de, Andries, F., Agt, H.M.E. van, Bijl, R.V., Boer, J.B. de,

Foets, M., Hoeymans, N., Jacobs, A.E., Kempen, G.I.J.M., Miedema, H.S., Tijhuis,

M.A.R., Haes, H.C.J.M. de

Which chronic conditions are associated with better or poorer quality of life?

Journal of Clinical Epidemiology: 53, 2000, nr. 9, p. p. 895-907

Table 1

Relative position of disease clusters according to physical/functional and psychological/social well-being; results from the literature ${ }^{\mathrm{a}}$

\begin{tabular}{|c|c|c|c|c|c|c|}
\hline \multirow[b]{3}{*}{ Disease clusters } & \multicolumn{3}{|l|}{ Physical/functional well-being } & \multicolumn{3}{|c|}{ Psychological/social well-being ${ }^{b}$} \\
\hline & \multirow{2}{*}{$\frac{\text { Positive }^{\mathrm{c}}}{\left.N \text { references }^{\mathrm{d}}\right]}$} & \multirow{2}{*}{$\frac{\text { Equivalent }}{N \text { [references }]}$} & \multirow{2}{*}{$\frac{\text { Negative }}{N \text { [references }]}$} & \multirow{2}{*}{$\frac{\text { Positive }}{N \text { [references }]}$} & \multirow{2}{*}{$\frac{\text { Equivalent }}{N \text { [references }]}$} & \multirow{2}{*}{$\frac{\text { Negative }}{N \text { [references }]}$} \\
\hline & & & & & & \\
\hline Hearing impairments & $1[19]$ & - & - & $1[9]$ & - & - \\
\hline Gastrointestinal diseases & $4[5,10,18,21]$ & - & $1[3]$ & $3[12,18,21]$ & - & $1[3]$ \\
\hline Visual impairments & $2[10,19]$ & - & $1[4]$ & $1[9]$ & - & - \\
\hline Endocrinologic conditions & $8[6,10,11,13,15,16,21,22]$ & $2[3,20]$ & $1[19]$ & $6[7,11,12,13,21,22]$ & $3[3,17,20]$ & $1[9]$ \\
\hline Chronic respiratory diseases & $6[10,13,15,16,19,21]$ & $2[3,4]$ & $1[5]$ & $2[13,21]$ & - & $3[3,4,9]$ \\
\hline Cancer & $4[4,6,15,16]$ & - & $3[5,10,19]$ & $3[4,7,9]$ & $1[17]$ & $1[12]$ \\
\hline Urogenital conditions & $1[10]$ & - & $1[4]$ & $1[9]$ & $1[13]$ & - \\
\hline Cardiovascular conditions & $5[5,10,11,13,16]$ & $1[20]$ & $5[3,6,15,19,21]$ & $4[11,12,13,21]$ & $2[17,20]$ & $2[3,9]$ \\
\hline Musculoskeletal conditions & $3[3,10,21]$ & $1[14]$ & $5[13,15,16,18,19]$ & $5[3,7,8,13,21]$ & $1[17]$ & $2[9,18]$ \\
\hline Renal diseases & - & - & $1[5]$ & $2[7,8]$ & - & - \\
\hline AIDS & - & $1[4]$ & - & - & - & $1[4]$ \\
\hline $\begin{array}{l}\text { Cerebrovascular/neurologic } \\
\text { conditions }\end{array}$ & $2[13,20]$ & $2[4,14]$ & $7[5,6,10,15,16,18,22]$ & $1[13]$ & $2[4,20]$ & $4[8,9,18,22]$ \\
\hline Psychiatric disorders & $1[13]$ & - & $4[10,11,20,21]$ & - & - & $5[7,11,13,20,21]$ \\
\hline
\end{tabular}

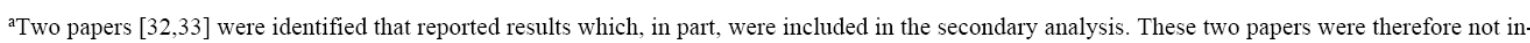
cluded in this overview.

${ }^{b}$ Results pertaining to satisfaction or judgements on intrusiveness are reported under the heading of psychological/social well-being, also if these ratings concern physical functioning. If the physical and psychosocial results are combined, these results are subsumed under the heading of psychosocial well-being.

${ }^{\mathrm{C} P o s i t i v e}$ is better well-being (significantly higher well-being score) in comparison to other chronic disease clusters; equivalent is equivalent well-being (insignificantly different well-being score) relative to other clusters; negative is poorer well-being (significantly lower well-being score) in comparison to other clusters. The level of statistical significance was set at $p<0.05[7-10,12,14,16,18]$. Two studies $[4,19]$, however, did not statistically test the differences among mean scores. In these cases, the conclusions of the authors were followed. In other studies $[3,5,6,11,13,15,17,20-22]$, disease categories had to be combined, in which case the mean scores were averaged. In these cases the comparisons could not be based on statistical significance.

-: not applicable.

${ }^{\mathrm{d}}$ The integers pertain to the papers cited in the references list. These studies include the following outcome variables: [3] Stewart et al. 1989: physical and mental functioning based on the MOS SF-36; [4] Schlenk et al. 1998: physical and mental functioning based on the MOS SF-36; [5] Bos van den, 1995: activity level based, in part, on a standardized questionnaire derived from ICIDH and QL studies; [6] Boult et al. 1994: functional limitations based, in part, on (Instrumental) Activities of Daily Living: [7] Cassileth et al. 1984: global and specific emotional well-being based on the Mental Health Index: [8] Devins et al. 1993: negative impact on social and personal functioning based on the Illness Intrusiveness Rating Scale; [9] Dorfman 1995: satisfaction with health, activities and social functioning based on the Retirement Descriptive Index; [10] Haber 1971: functional limitations and handicap based on the disability classification and functional limitations classification; [11] Hays et al. 1995: physical and mental functioning based on the MOS SF-36; [12] Hörnquist et al. 1992: emotional well-being, satisfaction with life domains based on nonstandardized instruments; [13] Lyons et al. 1994: physical and mental functioning based on the MOS SF-36; [14] Martinez et al. 1995: pain, functional limitation, helplessness, sleep and work based on a range of standardized instruments including the Health Assessment Questionnaire, the Fybromyalgia Immpact Questionnaire, the Arthritis Helplessness questionnaire and the Modified Post-Sleep Inventory; [15] Nusselder et al. 1996: functional limitation based on the Dutch National Survey of General Practice in '87/'88; [16] Picavet et al. 1994: mobility impairment based on health interviews of the Continuous Netherlands Health Interviews Surveys; [17] Rijken et al. 1995: global and emotional well-being based, in part, on the global items of the Rotterdam Symptom Checklist; [18] Rudick et al. 1992: functional, emotional and social functioning based on the Farmer Quality of Life Index; [19] Verbrugge et al. 1995: functional limitation based, in part, on the '83-'85 National Health Survey, the '85 National Ambulatory Medical Care Survey, and the '84 National Hospital Discharge Survey; [20] Vickrey et al. 1994: physical and mental functioning, global QL, based on the MOS SF-36 and the global item of the Dartmourth Coop Charts; [21] Wells et al. 1989: physical and social functioning, health perception, based on items of the Medical Outcomes Study and the RAND Health Insurance Study; [22] Hermann et al. 1996: physical and mental functioning based on the MOS SF-36. 
Sprangers, M.A.G., Regt, E.B. de, Andries, F., Agt, H.M.E. van, Bijl, R.V., Boer, J.B. de, Foets, M., Hoeymans, N., Jacobs, A.E., Kempen, G.I.J.M., Miedema, H.S., Tijhuis,

M.A.R., Haes, H.C.J.M. de

Which chronic conditions are associated with better or poorer quality of life?

Journal of Clinical Epidemiology: 53, 2000, nr. 9, p. p. 895-907

Table 2

Influence of sociodemographic characteristics and comorbidity: number of patient samples ${ }^{\mathrm{a}}$

\begin{tabular}{lllc}
\hline Characteristics & $\begin{array}{l}\text { QL } \\
\text { dimensions }\end{array}$ & $\begin{array}{l}\text { Physical } \\
\text { functioning }\end{array}$ & $\begin{array}{l}\text { Mental } \\
\text { functioning }\end{array}$ \\
\hline Age $^{\text {d,e }}$ & & & \\
Older $>$ younger & - & - & 3 \\
Older $<$ younger & 26 & 11 & 1 \\
Older = younger & 11 & 3 & 10 \\
Gender & & & \\
Male $>$ female & 29 & 2 & 9 \\
Male $<$ female & - & 1 & - \\
Male $=$ female & 7 & 11 & 5 \\
Education & & & \\
Low level $>$ high level & - & - & 1 \\
Low level $<$ high level & 26 & 12 & 7 \\
Low level $=$ high level & 12 & 3 & 7 \\
Living situation & & & \\
With partner $>$ other & 29 & 2 & 11 \\
With partner $<$ other & - & 4 & - \\
With partner $=$ other & 15 & 13 & 7 \\
Comorbidity & & & - \\
With $>$ without & - & - & 11 \\
With $<$ without & 35 & 13 & 2 \\
With $=$ without & 1 & - & \\
\hline
\end{tabular}

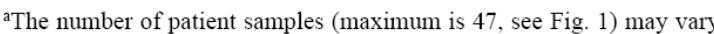
per background characteristic due to missing data and small subsample sizes (i.e., less than 10 patients).

${ }^{\mathrm{b}} \mathrm{The} \mathrm{QL}$ dimensions refer to the nine subscales of the SF-36 or the seven subscales of the SF-24 (see dependent measures).

${ }^{\mathrm{c}}$ Based on the physical and mental component summary scores, respectively.

${ }^{\mathrm{d} B e c a u s e}$ the data sets adopted different inclusion criteria with respect to age, different thresholds need to be employed. Older is 45-64 years, younger is $<45$ years for datasets 1,2 (asthma), 3, and 7; older is $>64$ years, younger is $<45$ years for datasets 2 (MS and neuromuscular disease), 4 , and 6 ; older is $>64$ years and younger is $45-64$ years for data set 8 . For data set 5, no distinction according to age could be made (see Appendix and Fig. 1).

e $>$ is better functioning: < is poorer functioning; = is comparable functioning.

fLow level is primary school and lower vocational education; high level is higher vocational education and university. 
Sprangers, M.A.G., Regt, E.B. de, Andries, F., Agt, H.M.E. van, Bijl, R.V., Boer, J.B. de,

Foets, M., Hoeymans, N., Jacobs, A.E., Kempen, G.I.J.M., Miedema, H.S., Tijhuis,

M.A.R., Haes, H.C.J.M. de

Which chronic conditions are associated with better or poorer quality of life?

Journal of Clinical Epidemiology: 53, 2000, nr. 9, p. p. 895-907

Table 3

Means and range of means of the QL dimensions and summed rank scores per disease category (dataset $\mathrm{a} / \mathrm{sample}$ size

\begin{tabular}{|c|c|c|c|c|c|c|c|c|}
\hline & $\begin{array}{l}\mathrm{PF} \\
\mathrm{M} \\
\text { range }^{\mathrm{b}}\end{array}$ & $\begin{array}{l}\text { PRF } \\
M \\
\text { range }\end{array}$ & $\begin{array}{l}\mathrm{BP} \\
\mathrm{M} \\
\text { range }\end{array}$ & $\begin{array}{l}\mathrm{GH} \\
\mathrm{M} \\
\text { range }\end{array}$ & $\begin{array}{l}\mathrm{V} \\
\mathrm{M} \\
\text { range }\end{array}$ & $\begin{array}{l}\mathrm{SF} \\
\mathrm{M} \\
\text { range }\end{array}$ & $\begin{array}{l}\mathrm{MH} \\
\mathrm{M} \\
\text { range }\end{array}$ & $\begin{array}{l}\text { Summed } \\
\text { rank scores }\end{array}$ \\
\hline \multicolumn{9}{|l|}{ Cardiovascular conditions } \\
\hline $\begin{array}{l}\text { Hypertension } \\
\quad(5 / 137 ; 8 / 1238)\end{array}$ & $\begin{array}{l}62.4 \\
46.0-80.1\end{array}$ & $\begin{array}{l}68.5 \\
50.7-86.7\end{array}$ & $\begin{array}{l}66.4 \\
18.1-89.7\end{array}$ & $\begin{array}{l}62.4 \\
56.8-77.5\end{array}$ & $\begin{array}{l}66.1 \\
61.8-78.8\end{array}$ & $\begin{array}{l}78.7 \\
68.2-89.4\end{array}$ & $\begin{array}{l}73.6 \\
67.9-82.8\end{array}$ & 7.5 \\
\hline $\begin{array}{l}\text { Heart conditions } \\
\qquad(3 / 57 ; 5 / 78 ; 8974)\end{array}$ & $\begin{array}{l}56.1 \\
41.7-86.0\end{array}$ & $\begin{array}{l}56.9 \\
40.0-82.5\end{array}$ & $\begin{array}{l}62.9 \\
21.4-83.9\end{array}$ & $\begin{array}{l}53.3 \\
43.6-68.5\end{array}$ & $\begin{array}{l}62.6 \\
50.1-72.0\end{array}$ & $\begin{array}{l}73.5 \\
63.5-86.7\end{array}$ & $\begin{array}{l}73.3 \\
61.0-80.4\end{array}$ & 13.5 \\
\hline \multicolumn{9}{|l|}{ Cerebrovascular/neurologic conditions } \\
\hline $\begin{array}{l}\text { Neuromuscular disease } \\
\quad(2 / 266 ; 2 / 348 ; 2 / 79 ; 2234)\end{array}$ & $\begin{array}{l}52.3 \\
\text { NA }\end{array}$ & $\begin{array}{l}62.7 \\
\mathrm{NA}\end{array}$ & $\begin{array}{l}78.4 \\
\text { NA }\end{array}$ & $\begin{array}{l}51.5 \\
\mathrm{NA}\end{array}$ & $\begin{array}{l}53.6 \\
\mathrm{NA}\end{array}$ & $\begin{array}{l}74.5 \\
\mathrm{NA}\end{array}$ & $\begin{array}{l}74.1 \\
\mathrm{NA}\end{array}$ & 13.5 \\
\hline Migraine $(8 / 489)$ & $\begin{array}{l}61.8 \\
47.9-82.0\end{array}$ & $\begin{array}{l}66.5 \\
41.0-91.3\end{array}$ & $\begin{array}{l}50.6 \\
35.5-55.6\end{array}$ & $\begin{array}{l}56.4 \\
48.2-70.5\end{array}$ & $\begin{array}{l}60.2 \\
53.7-69.4\end{array}$ & $\begin{array}{l}72.3 \\
57.5-85.3\end{array}$ & $\begin{array}{l}66.8 \\
60.5-73.8\end{array}$ & 15.5 \\
\hline Stroke $(3 / 38 ; 5 / 25 ; 8 / 159)$ & $\begin{array}{l}48.2 \\
32.0-95.0\end{array}$ & $\begin{array}{l}48.7 \\
16.7-100.0\end{array}$ & $\begin{array}{l}62.5 \\
23.7-80.7\end{array}$ & $\begin{array}{l}51.3 \\
40.0-69.7\end{array}$ & $\begin{array}{l}57.8 \\
35.0-68.9\end{array}$ & $\begin{array}{l}62.4 \\
49.8-87.5\end{array}$ & $\begin{array}{l}71.2 \\
59.6-80.0\end{array}$ & 23.5 \\
\hline Multiple sclerosis $(2 / 836 ; 8 / 12)$ & $\begin{array}{l}44.2 \\
3.3-68.0\end{array}$ & $\begin{array}{l}50.2 \\
0.0-66.7\end{array}$ & $\begin{array}{l}75.0 \\
25.0-86.9\end{array}$ & $\begin{array}{l}46.1 \\
26.7-55.5\end{array}$ & $\begin{array}{l}47.6 \\
36.7-62.5\end{array}$ & $\begin{array}{l}65.1 \\
20.0-80.0\end{array}$ & $\begin{array}{l}71.1 \\
63.0-78.4\end{array}$ & 26.0 \\
\hline Parkinson/epilepsy (8/89) & $\begin{array}{l}49.2 \\
30.8-70.1\end{array}$ & $\begin{array}{l}45.7 \\
31.3-67.3\end{array}$ & $\begin{array}{l}62.0 \\
19.3-50.0\end{array}$ & $\begin{array}{l}50.2 \\
42.5-62.5\end{array}$ & $\begin{array}{l}58.6 \\
51.0-70.7\end{array}$ & $\begin{array}{l}66.9 \\
58.3-86.4\end{array}$ & $\begin{array}{l}67.7 \\
57.1-78.7\end{array}$ & 26.5 \\
\hline \multicolumn{9}{|l|}{ Endocrinologic conditions } \\
\hline Thyroid gland impairments $(8 / 187)$ & $\begin{array}{l}59.4 \\
44.4-81.8\end{array}$ & $\begin{array}{l}64.4 \\
48.3-90.0\end{array}$ & $\begin{array}{l}62.5 \\
13.6-45.3\end{array}$ & $\begin{array}{l}59.3 \\
55.0-78.2\end{array}$ & $\begin{array}{l}63.4 \\
59.7-77.5\end{array}$ & $\begin{array}{l}75.1 \\
64.8-90.3\end{array}$ & $\begin{array}{l}70.5 \\
65.0-81.0\end{array}$ & 9.5 \\
\hline Diabetes mellitus $(3 / 61 ; 5 / 38 ; 8379)$ & $\begin{array}{l}58.0 \\
45.0-80.0\end{array}$ & $\begin{array}{l}56.9 \\
6.3-90.6\end{array}$ & $\begin{array}{l}64.1 \\
67.3-87.8\end{array}$ & $\begin{array}{l}54.3 \\
36.4-69.6\end{array}$ & $\begin{array}{l}62.8 \\
50.4-72.9\end{array}$ & $\begin{array}{l}71.8 \\
46.9-89.1\end{array}$ & $\begin{array}{l}73.2 \\
62.9-83.9\end{array}$ & 11.5 \\
\hline \multicolumn{9}{|l|}{ Gastrointestinal conditions } \\
\hline $\begin{array}{l}\text { Ulcer in stomach or duodenum/ } \\
\text { bowel disease }(8 / 305)\end{array}$ & $\begin{array}{l}57.1 \\
44.8-78.8\end{array}$ & $\begin{array}{l}56.7 \\
38.0-82.6\end{array}$ & $\begin{array}{l}52.7 \\
26.7-55.0\end{array}$ & $\begin{array}{l}52.4 \\
46.8-71.6\end{array}$ & $\begin{array}{l}62.5 \\
56.6-74.6\end{array}$ & $\begin{array}{l}71.7 \\
62.9-91.6\end{array}$ & $\begin{array}{l}70.3 \\
66.1-76.6\end{array}$ & 9.0 \\
\hline $\begin{array}{l}\text { Liver disease/gallstones/gall } \\
\text { bladder inflammation }(8 / 137)\end{array}$ & $\begin{array}{l}51.6 \\
35.4-83.3\end{array}$ & $\begin{array}{l}51.9 \\
40.4-100.0\end{array}$ & $\begin{array}{l}53.4 \\
18.2-50.3\end{array}$ & $\begin{array}{l}53.7 \\
50.5-80.0\end{array}$ & $\begin{array}{l}61.5 \\
57.7-80.6\end{array}$ & $\begin{array}{l}66.7 \\
62.1-90.9\end{array}$ & $\begin{array}{l}71.1 \\
66.4-84.7\end{array}$ & 12.0 \\
\hline \multicolumn{9}{|l|}{ Musculoskeletal conditions } \\
\hline Rheumatoid arthritis $(1 / 1061 ; 5 / 30)$ & $\begin{array}{l}50.2 \\
42.5-87.5\end{array}$ & $\begin{array}{l}46.0 \\
32.7-87.5\end{array}$ & $\begin{array}{l}56.9 \\
42.9-81.6\end{array}$ & $\begin{array}{l}49.5 \\
41.7-75.0\end{array}$ & $\begin{array}{l}54.3 \\
41.3-85.0\end{array}$ & $\begin{array}{l}73.2 \\
57.1-87.5\end{array}$ & $\begin{array}{l}72.8 \\
43.0-78.0\end{array}$ & 11.0 \\
\hline Back impairments $(5 / 41 ; 8903)$ & $\begin{array}{l}49.4 \\
36.6-61.8\end{array}$ & $\begin{array}{l}52.2 \\
41.7-90.0\end{array}$ & $\begin{array}{l}49.4 \\
40.4-78.4\end{array}$ & $\begin{array}{l}55.5 \\
50.8-78.0\end{array}$ & $\begin{array}{l}61.5 \\
56.9-83.0\end{array}$ & $\begin{array}{l}71.6 \\
61.3-95.0\end{array}$ & $\begin{array}{l}70.8 \\
64.0-93.6\end{array}$ & 14.5 \\
\hline $\begin{array}{l}\text { Osteoarthritis/other joint complaints } \\
\quad(5 / 97 ; 4 / 336 ; 8 / 1195)\end{array}$ & $\begin{array}{l}49.3 \\
33.4-66.9\end{array}$ & $\begin{array}{l}51.4 \\
22.4-78.9\end{array}$ & $\begin{array}{l}50.0 \\
38.0-86.5\end{array}$ & $\begin{array}{l}55.3 \\
36.7-72.3\end{array}$ & $\begin{array}{l}59.7 \\
45.0-79.2\end{array}$ & $\begin{array}{l}70.0 \\
50.8-92.3\end{array}$ & $\begin{array}{l}69.9 \\
61.5-84.9\end{array}$ & 16.5 \\
\hline \multicolumn{9}{|l|}{ Psychiatric disorders } \\
\hline Alcohol problems (7/491) & $\begin{array}{l}92.5 \\
85.9-95.9\end{array}$ & $\begin{array}{l}86.7 \\
79.0-94.6\end{array}$ & $\begin{array}{l}84.4 \\
78.3-90.5\end{array}$ & $\begin{array}{l}72.2 \\
65.7-79.9\end{array}$ & $\begin{array}{l}68.1 \\
60.9-74.6\end{array}$ & $\begin{array}{l}86.5 \\
78.8-91.5\end{array}$ & $\begin{array}{l}78.0 \\
69.7-83.7\end{array}$ & 7.0 \\
\hline Anxiety disorders $(7 / 915)$ & $\begin{array}{l}87.6 \\
80.0-93.0\end{array}$ & $\begin{array}{l}79.3 \\
70.8-100.0\end{array}$ & $\begin{array}{l}78.3 \\
72.1-87.5\end{array}$ & $\begin{array}{l}63.8 \\
59.4-67.9\end{array}$ & $\begin{array}{l}56.2 \\
51.1-62.5\end{array}$ & $\begin{array}{l}73.3 \\
66.8-78.0\end{array}$ & $\begin{array}{l}65.6 \\
58.9-73.8\end{array}$ & 14.0 \\
\hline Depression $(7 / 572)$ & $\begin{array}{l}85.2 \\
77.2-95.6\end{array}$ & $\begin{array}{l}69.8 \\
63.7-88.8\end{array}$ & $\begin{array}{l}72.6 \\
64.4-88.7\end{array}$ & $\begin{array}{l}61.3 \\
52.8-75.1\end{array}$ & $\begin{array}{l}51.3 \\
40.6-60.8\end{array}$ & $\begin{array}{l}71.2 \\
63.8-84.0\end{array}$ & $\begin{array}{l}59.1 \\
48.4-67.7\end{array}$ & 21.0 \\
\hline
\end{tabular}

$\mathrm{PF}=$ physical functioning: $\mathrm{PRF}=$ physical role functioning: $\mathrm{BP}=$ bodily pain: $\mathrm{GH}=$ general health: $\mathrm{V}=$ vitality: $\mathrm{SF}=$ social functioning: $\mathrm{MH}=$ mental health. $\mathrm{NA}=$ not available.

${ }^{\mathrm{a}}$ For a description of data sets, see appendix A.

${ }^{\mathrm{b}}$ The range of the smallest and largest means.

${ }^{\mathrm{c} A}$ lower summed rank score indicates better functioning. 
Sprangers, M.A.G., Regt, E.B. de, Andries, F., Agt, H.M.E. van, Bijl, R.V., Boer, J.B. de,

Foets, M., Hoeymans, N., Jacobs, A.E., Kempen, G.I.J.M., Miedema, H.S., Tijhuis,

M.A.R., Haes, H.C.J.M. de

Which chronic conditions are associated with better or poorer quality of life?

Journal of Clinical Epidemiology: 53, 2000, nr. 9, p. p. 895-907

Table 4

Means and range of means of the QL dimensions and summed rank scores per disease cluster

\begin{tabular}{|c|c|c|c|c|c|c|c|c|}
\hline & $\begin{array}{l}\mathrm{PF} \\
\mathrm{M} \\
\text { range }^{\mathrm{a}}\end{array}$ & $\begin{array}{l}\mathrm{PRF} \\
\mathrm{M} \\
\text { range }\end{array}$ & $\begin{array}{l}\mathrm{BP} \\
\mathrm{M} \\
\text { range }\end{array}$ & $\begin{array}{l}\mathrm{GH} \\
\mathrm{M} \\
\text { range }\end{array}$ & $\begin{array}{l}\mathrm{V} \\
\mathrm{M} \\
\text { range }\end{array}$ & $\begin{array}{l}\mathrm{SF} \\
\mathrm{M} \\
\text { range }\end{array}$ & $\begin{array}{l}\mathrm{MH} \\
\mathrm{M} \\
\text { range }\end{array}$ & $\begin{array}{l}\text { Summed } \\
\text { rank score }\end{array}$ \\
\hline Urogenital conditions & $\begin{array}{l}67.6 \\
57.5-84.5\end{array}$ & $\begin{array}{l}72.4 \\
60.8-95.0\end{array}$ & $\begin{array}{l}69.0 \\
18.3-34.3\end{array}$ & $\begin{array}{l}62.9 \\
59.1-77.4\end{array}$ & $\begin{array}{l}68.9 \\
66.3-79.4\end{array}$ & $\begin{array}{l}79.3 \\
73.0-86.3\end{array}$ & $\begin{array}{l}77.6 \\
74.0-82.0\end{array}$ & 15.5 \\
\hline Hearing impairments & $\begin{array}{l}61.6 \\
53.6-88.1\end{array}$ & $\begin{array}{l}63.8 \\
43.2-90.6\end{array}$ & $\begin{array}{l}73.8 \\
71.2-89.0\end{array}$ & $\begin{array}{l}59.6 \\
47.0-76.3\end{array}$ & $\begin{array}{l}61.8 \\
39.0-77.5\end{array}$ & $\begin{array}{l}76.6 \\
56.8-82.6\end{array}$ & $\begin{array}{l}73.1 \\
58.8-86.0\end{array}$ & 29.5 \\
\hline Psychiatric disorders & $\begin{array}{l}88.4 \\
77.2-95.9\end{array}$ & $\begin{array}{l}78.6 \\
63.7-100.0\end{array}$ & $\begin{array}{l}78.4 \\
64.4-90.5\end{array}$ & $\begin{array}{l}65.8 \\
52.8-79.9\end{array}$ & $\begin{array}{l}58.5 \\
40.6-74.6\end{array}$ & $\begin{array}{l}77.0 \\
63.8-91.5\end{array}$ & $\begin{array}{l}67.6 \\
48.4-83.7\end{array}$ & 30.5 \\
\hline Dermatologic conditions & $\begin{array}{l}62.6 \\
46.5-85.3\end{array}$ & $\begin{array}{l}69.3 \\
57.3-88.9\end{array}$ & $\begin{array}{l}64.1 \\
14.8-42.4\end{array}$ & $\begin{array}{l}62.1 \\
57.8-78.8\end{array}$ & $\begin{array}{l}66.5 \\
62.4-74.8\end{array}$ & $\begin{array}{l}77.0 \\
65.4-91.6\end{array}$ & $\begin{array}{l}72.1 \\
66.5-78.8\end{array}$ & 32 \\
\hline Cardiovascular conditions & $\begin{array}{l}59.3 \\
41.7-86.0\end{array}$ & $\begin{array}{l}62.7 \\
40.0-86.7\end{array}$ & $\begin{array}{l}64.7 \\
18.1-89.7\end{array}$ & $\begin{array}{l}57.9 \\
43.6-77.5\end{array}$ & $\begin{array}{l}64.4 \\
50.1-78.8\end{array}$ & $\begin{array}{l}76.1 \\
63.5-89.4\end{array}$ & $\begin{array}{l}73.5 \\
61.0-82.8\end{array}$ & 37 \\
\hline Cancer & $\begin{array}{l}67.4 \\
40.0-86.0\end{array}$ & $\begin{array}{l}60.3 \\
30.4-90.0\end{array}$ & $\begin{array}{l}68.6 \\
20.1-95.3\end{array}$ & $\begin{array}{l}56.9 \\
46.4-69.4\end{array}$ & $\begin{array}{l}62.6 \\
53.2-73.1\end{array}$ & $\begin{array}{l}74.8 \\
54.0-97.9\end{array}$ & $\begin{array}{l}72.2 \\
59.1-86.0\end{array}$ & 43 \\
\hline Endocrinologic conditions & $\begin{array}{l}58.7 \\
44.4-81.8\end{array}$ & $\begin{array}{l}60.7 \\
6.3-90.9\end{array}$ & $\begin{array}{l}63.3 \\
13.6-87.8\end{array}$ & $\begin{array}{l}56.8 \\
36.4-78.2\end{array}$ & $\begin{array}{l}63.1 \\
50.4-77.5\end{array}$ & $\begin{array}{l}72.7 \\
46.9-90.3\end{array}$ & $\begin{array}{l}72.5 \\
62.9-83.9\end{array}$ & 49.5 \\
\hline Visual impairments & $\begin{array}{l}56.5 \\
51.5-82.5\end{array}$ & $\begin{array}{l}59.6 \\
50.0-100.0\end{array}$ & $\begin{array}{l}70.7 \\
63.4-84.4\end{array}$ & $\begin{array}{l}58.1 \\
57.2-72.5\end{array}$ & $\begin{array}{l}52.9 \\
43.3-59.0\end{array}$ & $\begin{array}{l}72.1 \\
62.5-87.5\end{array}$ & $\begin{array}{l}72.6 \\
62.0-76.0\end{array}$ & 51 \\
\hline Chronic respiratory diseases & $\begin{array}{l}65.4 \\
38.4-89.6\end{array}$ & $\begin{array}{l}62.5 \\
25.0-100.0\end{array}$ & $\begin{array}{l}72.7 \\
15.8-100.0\end{array}$ & $\begin{array}{l}52.0 \\
34.2-67.9\end{array}$ & $\begin{array}{l}58.4 \\
32.5-75.0\end{array}$ & $\begin{array}{l}72.7 \\
50.0-90.6\end{array}$ & $\begin{array}{l}70.8 \\
51.7-82.0\end{array}$ & 52.5 \\
\hline Gastrointestinal conditions & $\begin{array}{l}55.4 \\
35.4-83.3\end{array}$ & $\begin{array}{l}55.2 \\
38.0-100.0\end{array}$ & $\begin{array}{l}52.9 \\
18.2-55.0\end{array}$ & $\begin{array}{l}52.8 \\
46.8-80.0\end{array}$ & $\begin{array}{l}62.2 \\
56.6-80.6\end{array}$ & $\begin{array}{l}70.2 \\
62.1-91.6\end{array}$ & $\begin{array}{l}70.5 \\
66.1-84.7\end{array}$ & 69 \\
\hline Cerebrovascular/Neurologic conditions & $\begin{array}{l}51.1 \\
3.3-95.0\end{array}$ & $\begin{array}{l}54.8 \\
0.0-100.0\end{array}$ & $\begin{array}{l}69.7 \\
19.3-86.9\end{array}$ & $\begin{array}{l}51.1 \\
26.7-70.5\end{array}$ & $\begin{array}{l}55.6 \\
35.0-70.7\end{array}$ & $\begin{array}{l}68.2 \\
20.0-87.5\end{array}$ & $\begin{array}{l}70.2 \\
57.1-80.0\end{array}$ & 74 \\
\hline Renal diseases & $\begin{array}{l}51.7 \\
34.2-79.2\end{array}$ & $\begin{array}{l}51.6 \\
37.8-95.8\end{array}$ & $\begin{array}{l}55.9 \\
18.8-52.7\end{array}$ & $\begin{array}{l}48.5 \\
44.5-70.8\end{array}$ & $\begin{array}{l}60.5 \\
54.0-74.1\end{array}$ & $\begin{array}{l}69.1 \\
61.7-85.0\end{array}$ & $\begin{array}{l}72.4 \\
65.4-85.7\end{array}$ & 75 \\
\hline Musculoskeletal conditions & $\begin{array}{l}49.6 \\
33.4-87.5\end{array}$ & $\begin{array}{l}49.9 \\
22.4-90.0\end{array}$ & $\begin{array}{l}52.1 \\
38.0-86.5\end{array}$ & $\begin{array}{l}53.4 \\
36.7-78.0\end{array}$ & $\begin{array}{l}58.5 \\
41.3-85.0\end{array}$ & $\begin{array}{l}71.6 \\
50.8-95.0\end{array}$ & $\begin{array}{l}71.2 \\
43.0-93.6\end{array}$ & 78.5 \\
\hline
\end{tabular}

$\mathrm{PF}=$ physical functioning; $\mathrm{RPF}=$ physical role functioning; $\mathrm{BP}=$ bodily pain; $\mathrm{GH}=$ general health; $\mathrm{V}=$ vitality; $\mathrm{SF}=$ social functioning; $\mathrm{MH}=$ mental health.

aThe range of the smallest and largest means.

${ }^{\mathrm{b}} \mathrm{A}$ lower (summed) rank score indicates better functioning.

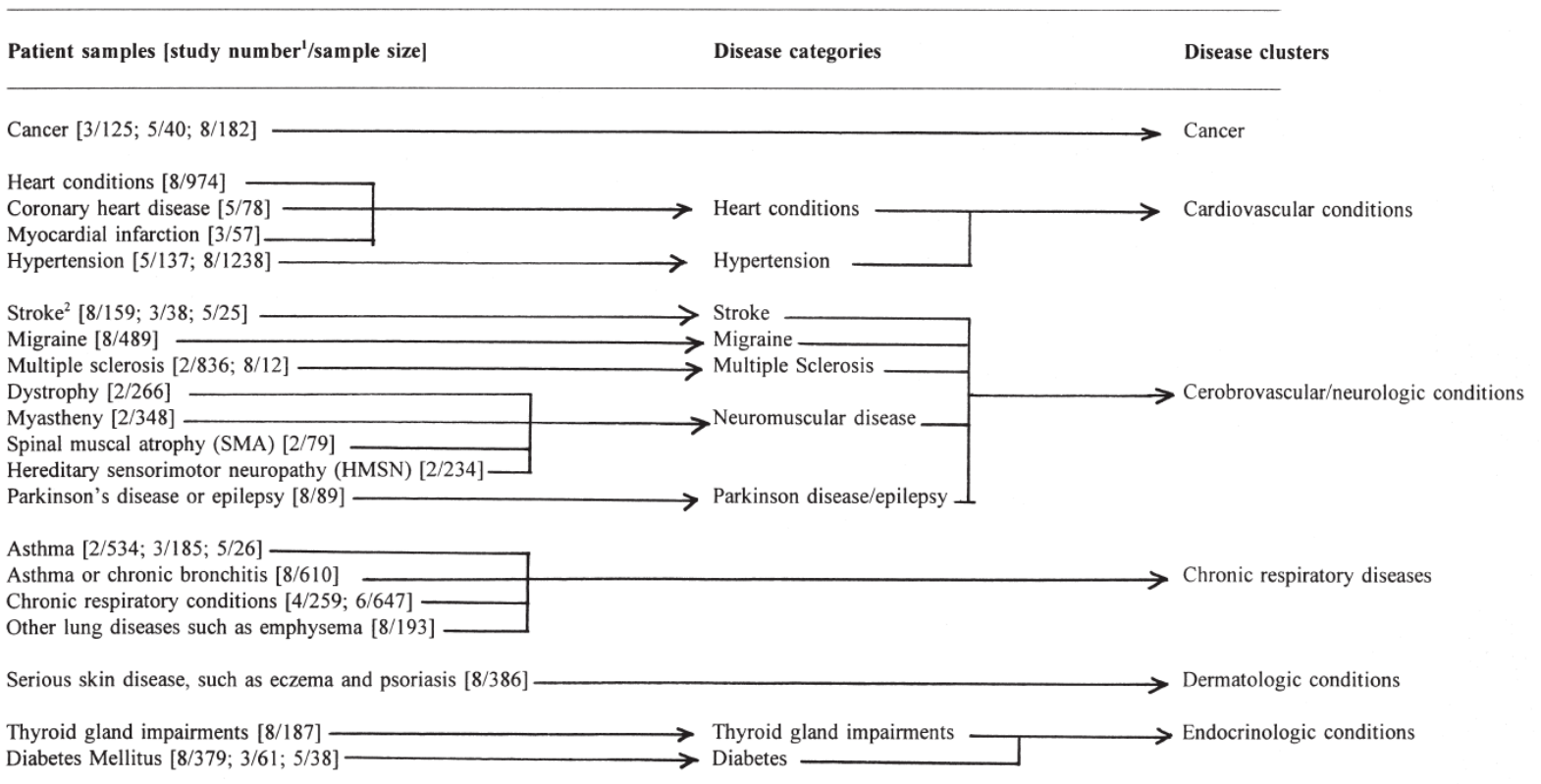

Fig. 1. Composition of patient samples, disease categories, and disease clusters. 
Sprangers, M.A.G., Regt, E.B. de, Andries, F., Agt, H.M.E. van, Bijl, R.V., Boer, J.B. de,

Foets, M., Hoeymans, N., Jacobs, A.E., Kempen, G.I.J.M., Miedema, H.S., Tijhuis,

M.A.R., Haes, H.C.J.M. de

Which chronic conditions are associated with better or poorer quality of life?

Journal of Clinical Epidemiology: 53, 2000, nr. 9, p. p. 895-907

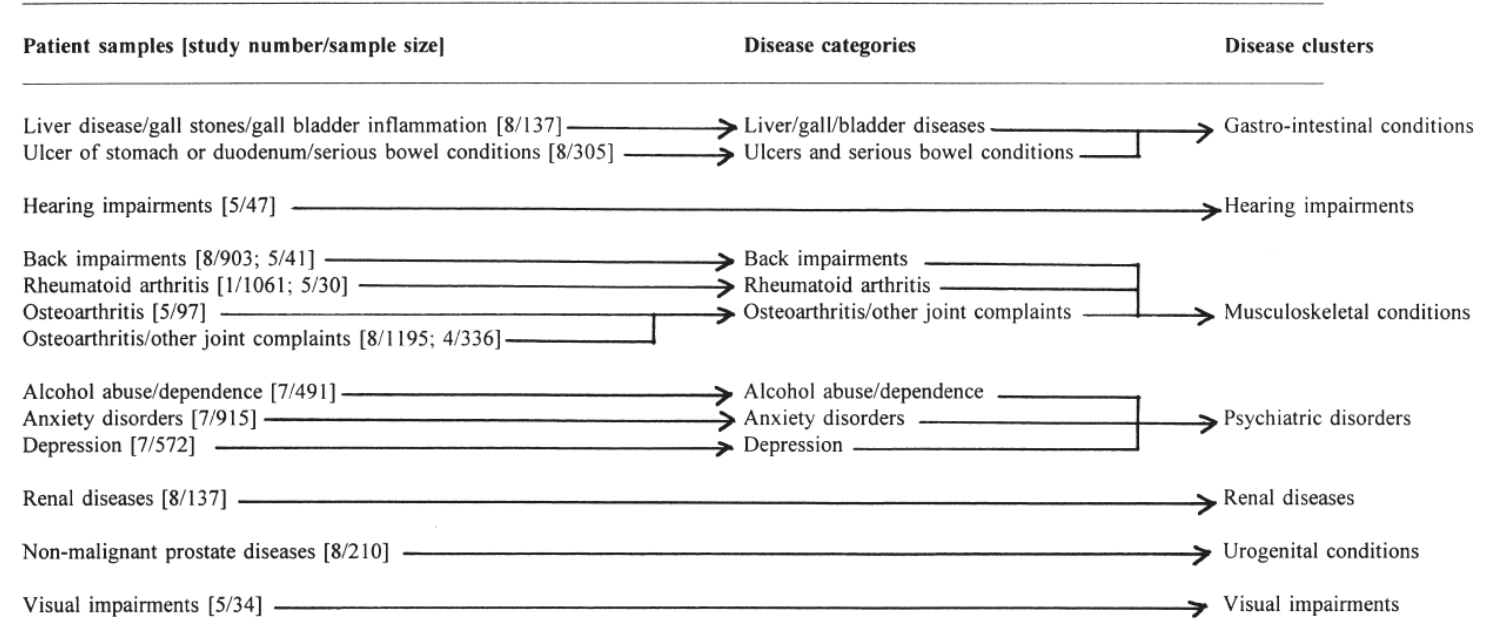

For a description of data sets, see Appendix.

There is some dispute whether stroke should be subsumed under cardiologic or neurologic conditions. Since the consequences of stroke have striking similarity with those of neurologic conditions and stroke patients are frequently treated at neurologic departments, stroke is here subsumed under neurologic conditions.

Fig. 1. Continued.

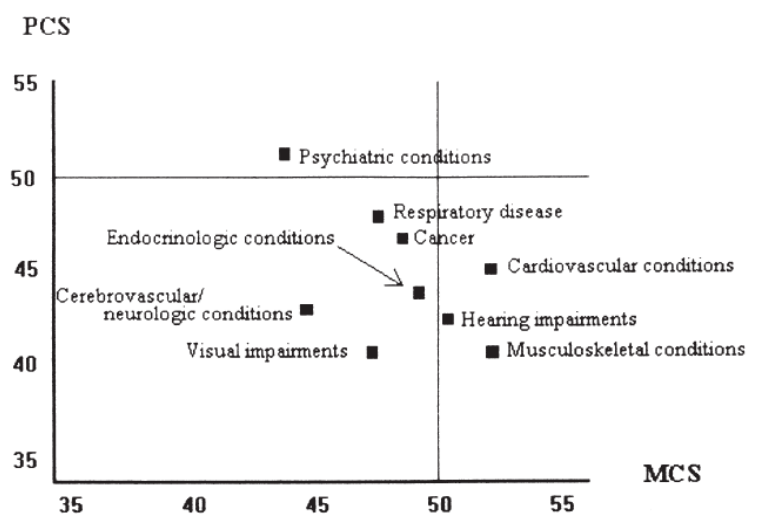

Fig. 2. The position of the disease clusters with respect to physical (PCS) and mental (MCS) functioning.

\section{REFERENCES}

[1] US Department of Health and Human Services, Public Health Service. Healthy People 2000: Midcourse Review and 1995 Revisions. Boston: Jones and Bartlet, 1996.

[2] Wetenschappelijke Raad voor het Regeringsbeleid. Volkgezondheidszorg. SDU Uitgevers, Den Haag, 1997.

[3] Stewart AL, Greenfield S, Hays RD, et al. Functional status and wellbeing of patients with chronic conditions. Results from the Medical Outcomes Study. JAMA 1989;262:907-13.

[4] Schlenk EA, Erlen JA, Dunbar-Jacob J, et al. Health-related quality of life in chronic disorders: a comparison across studies using the MOS SF-36. Qual Life Res 1998;7:57-75.

[5] Bos van den GAM. The burden of chronic diseases in terms of disability, use of health care and healthy life expectancies. Eur J Publ Health 1995;5:29-34.

[6] Boult C, Kane RL, Louis TA, Boult L, McCaffrey D. Chronic conditions that lead to functional limitation in the elderly. J Gerontol Med Sci 1994;49:M28-M36.

[7] Cassileth BR, Lusk EJ, Strouse TB, et al. Psychosocial status in chronic illness. A comparative analysis of six diagnostic groups. N Engl J Med 1984;311:506-11.

[8] Devins GM, Edworthy SM, Seland TP, Klein GM, Paul LC, Mandin H. Differences in illness intrusiveness across rheumatoid arthritis, end-stage renal disease, and multiple sclerosis. J Nerv Ment Dis 1993;181:377-81.

[9] Dorfman LT. Health conditions and perceived quality of life in retirement. Health Soc Work 1995;20:192-9. 
Sprangers, M.A.G., Regt, E.B. de, Andries, F., Agt, H.M.E. van, Bijl, R.V., Boer, J.B. de,

Foets, M., Hoeymans, N., Jacobs, A.E., Kempen, G.I.J.M., Miedema, H.S., Tijhuis,

M.A.R., Haes, H.C.J.M. de

Which chronic conditions are associated with better or poorer quality of life?

Journal of Clinical Epidemiology: 53, 2000, nr. 9, p. p. 895-907

[10] Haber LD. Disabling effects of chronic disease and impairment. J Chron Dis 1971;24:469-87.

[11] Hays RD, Wells KB, Sherbourne CD, Rogers W, Spritzer K. Functioning and well-being outcomes of patients with depression compared with chronic general medical illnesses. Arch Gen Psychiatry 1995;52:11-9.

[12] Hörnquist JO, Hansson B, Åkerlind I, Larson J. Severity of disease and quality of life: a comparison in patients with cancer and benign disease. Qual Life Res 1992;1:135-41.

[13] Lyons RA, Vui Lo S, Littlepage BNC. Comparative health status of patients with 11 common illnesses in Wales. J Epidemiol Community Health 1994;48:388-90.

[14] Martinez JE, Ferraz MB, Inoe Sato E, Atra E. Fibromyalgia versus rheumatoid arthritis: a longitudinal comparison of the quality of Life. J Rheumatol 1995;22:270-4.

[15] Nusselder WJ, Velden van der K, Sonsbeek van JLA, Bos van den GAM. The elimination of selected chronic diseases in a population: the compression and expansion of morbidity. Am J Public Health 1996;86:187-94.

[16] Picavet HSJ, Bos van den GAM. Beweeglijkheidsbeperkingen en chronische aandoeningen in de Nederlandse bevolking. Maandbericht Gezondheidsstatistiek van het Centraal Bureau voor de Statistiek. 1994;9:5-11.

[17] Rijken M, Komproe IH, Ros WJG, Winnubst JAM, Heesch NCA. Subjective well-being of elderly women: conceptual differences between cancer patients, women suffering from chronic ailments and healthy women. Br J Clin Psychol 1995;34:289-300.

[18] Rudick RA, Miller D, Clough JD, Gragg LA, Farmer RG. Quality of life in multiple sclerosis. Comparisons with inflammatory bowel disease and rheumaroid arthritis. Arch Neurol 1992;49:123742.

[19] Verbrugge LM, Patrick D. Seven chronic conditions: their impact on US adults' activity levels and use of medical services. Am J Public Health 1995;85:173-82.

[20] Vickrey BG, Hays RD, Rausch R, Sutherling WW, Engel J, Brook RH. Quality of life of epilepsy surgery patients as compared with outpatients with hypertension, diabetes, heart disease, and/or depressive symptoms. Epilepsia 1994;35:597-607.

[21] Wells KB, Stewart A, Hays RD, et al. The functioning and well-being of depressed patients. Results from the Medical Outcomes Study. JAMA 1989;262:914-9.

[22] Hermann BP, Vickrey B, Hays RD, et al. A comparison of healthrelated quality of life in patients with epilepsy, diabetes and multiple sclerosis. Epilepsy Res 1996;25:113-8.

[23] Cella DF, Tulsky DS. Measuring quality of life today: methodological aspects. Oncology 1990;4:29-38.

[24] Siegrist J, Junge A. Conceptual and methodological problems in research on the quality of life in clinical medicine. Soc Sci Med 1989;29:463-8.

[25] McHorney CA, Ware JE, Raczek AE. The MOS 36-item short-form health survey (SF-36): II. Psychometric and clinical tests of validity in measuring physical and mental health constructs. Med Care, 1993;31:247-63.

[26] Shiely JC, Bayliss MS, Keller SD, Tsai C, Ware JE Jr. SF-36 Health Survey Annoted Bibliography: First Edition (1988-1995). Boston: The Health Institute, New England Medical Center, 1996.

[27] Zee van der KI, Sanderman R, Heyink J. A comparison of two multidimensional measures of health status: the Nottingham Health Profile and the RAND 36-item health survey. 1.0. Qual Life Res 1996;5:165-74.

[28] Aaronson NK, Muller M, Cohen PDA, et al. Translation, validation and norming of the Dutch language version of the SF-36 Health Survey in community and chronic disease populations. J Clin Epidemiol 1998;51:1055-68.

[29] Ware JE, Jr. SF-36 Health Survey. Manual \& Interpretation Guide. Boston: The Health Institute, New England Medical Center, 1993.

[30] Stewart AL, Hays RD, Ware JE. The MOS Short-Form General Health Survey—reliability and validity in a patient population. Med Care 1988;26:724-35.

[31] Kempen GIJM, Brilman El, Heyink JW, Ormel J. MOS Short-Form General Health Survey (SF20). Groningen: Noordelijk Centrum voor Gezondheidsvraagstukken, 1995.

[32] Ware JE, Keller SD. Interpreting general health measures. In: Spilker B, editor. Quality of Life and Pharmacoeconomics in Clinical Trials, 2nd ed. Philadelphia: Lippincott-Raven Publishers, 1996.

[33] Kempen GIJM, Ormel J, Brilman E, Relyveld J. Adaptive responses among Dutch elderly: the impact of eight chronic medical conditions on health-related quality of life. Am J Public Health 1997;87:38-44.

[34] Edlinger M, Hoeymans N, Tijhuis M, Feskens EJM. De kwaliteit van leven (RAND-36) in twee Nederlandse populaties. Tijdschr Gezondheidswetensch 1998;76:211-9. 
Sprangers, M.A.G., Regt, E.B. de, Andries, F., Agt, H.M.E. van, Bijl, R.V., Boer, J.B. de,

Foets, M., Hoeymans, N., Jacobs, A.E., Kempen, G.I.J.M., Miedema, H.S., Tijhuis,

M.A.R., Haes, H.C.J.M. de

Which chronic conditions are associated with better or poorer quality of life?

Journal of Clinical Epidemiology: 53, 2000, nr. 9, p. p. 895-907

[35] Hoeymans N, Feskens EJM, Bos van den GAM, Kromhout D. Nonresponse bias in a study of cardiovascular diseases, functional status and self-rated health among elderly men. Age Ageing 1998;27:35-40.

[36] Ware JE, Gandek B, Kosinski M, et al. The equivalence of SF-36 summary health scores estimated using standard and country-specific algorithms in 10 countries: results from the IQOLA project. J Clin Epidemiol 1998;51:1167-70.

[37] Bijl RV, Zessen van G, Ravelli A, Rijk de C, Langendoen Y. The Netherlands Mental Health Survey and Incidence Study (NEMESIS): objectives and design. Soc Psychiatry Psychiatr Epidemiol (in press).

\section{APPENDIX: DESCRIPTION OF THE DATA SETS}

\section{TNO-Prevention and Health Study}

Context. Data were collected in the context of the study "Skills of individuals with rheumatoid arthritis" conducted in 1996.

Sample. Age: $16-60$ years, identified by 17 rheumatology practices, the sample was stratified by age and gender, 1693 patients were approached by their treating rheumatologist, 1061 (63\%) responded positively.

Assessment of diagnosis. Rheumatoid arthritis was diagnosed by the treating physician.

Comorbidity was assessed by means of a self-report list including 22 conditions.

\section{NIA TNO Project}

Context. Three data sets were provided, including those on a) neuromuscular conditions, collected in the context of the study "Working with a neuromuscular condition" in 1994; b) asthma, collected in the study "Asthma and work" in 1996; and c) multiple sclerosis in the study "MS and work" in 1996.

Sample. Neuromuscular conditions: Age: $16-65$ years, identified either by their treating specialist (N $=1299)$ or by the patient society of neuromuscular diseases $(\mathrm{N}=1080) ; 996$ completed questionnaires were returned ( $42 \%$ in case there is no overlap between the two patient samples, which cannot be established due to privacy regulations). Data are included of patients with dystrophy $(\mathrm{N}=266)$, myastheny $(\mathrm{N}=348)$, spinal muscular atrophy (SMA) $(\mathrm{N}=79)$, or hereditary sensorimotor neuropathy (HMSN) $(\mathrm{N}=234)$. Asthma: Age: $18-45$ years, identified by pulmonologists in five provinces of the Netherlands (i.e., Drenthe, Groningen, Limburg, Noord-Holland, Zuid-Holland). Of the 1335 patients approached, $534(40 \%)$ returned completed questionnaires. Multiple sclerosis: Age: $18-65$ years identified via the patient society of multiple sclerosis. A sample of 1045 patients was approached, $836(80 \%)$ returned completed questionnaires.

Assessment of diagnosis. Neuromuscular conditions were diagnosed by the specialist or by means of self-report, dependent on the procedure of accrual. Comorbidity was assessed by means of the question "Do you have any other chronic condition?" The diagnosis asthma was established by the treating physician. Comorbidity was not assessed. The diagnosis multiple sclerosis was assessed by selfreport. Comorbidity was assessed by means of the question "Do you have any other chronic conditions?"

\section{MORGEN Project}

Context. Data were collected in the context of the study "Monitoring Risk factors and Heath in the Netherlands (MORGEN)." This study purported to examine the health and prevalence of risk factors in a sample of the Dutch population during 1993 to 1997. The data used in this article were collected in 1995 .

Sample. Age: $20-60$ years, living in the cities of Amsterdam, Maastricht, or Doetinchem. The response rate was on average $43 \%, 4946$ individuals were included. Only the data of individuals with a myocardial infarction $(n=57)$, stroke $(n=38)$, diabetes $(n=61)$, asthma $(n=185)$, or cancer $(n=$ $125)$ were included in the current article.

Assessment of diagnosis. The presence of these chronic conditions was assessed by means of selfreport (e.g., "Have you ever had a heart attack"). Comorbidity was defined as the presence of two or more of these five conditions. This implies that respondents may have been included in more than one disease category. 
Sprangers, M.A.G., Regt, E.B. de, Andries, F., Agt, H.M.E. van, Bijl, R.V., Boer, J.B. de,

Foets, M., Hoeymans, N., Jacobs, A.E., Kempen, G.I.J.M., Miedema, H.S., Tijhuis,

M.A.R., Haes, H.C.J.M. de

Which chronic conditions are associated with better or poorer quality of life?

Journal of Clinical Epidemiology: 53, 2000, nr. 9, p. p. 895-907

\section{NIVEL Study}

Context. The data forwarded by the NIVEL research institute originate from a study into the continuity of care of chronically ill patients. The objective was to develop an instrument to measure continuity of care from the patients' perspective. The data used in this article were collected at the end of 1995 and the beginning of 1996.

Sample. Age: 18 years and older, identified either by GPs or specialists in the regions surrounding the cities of Amsterdam and Tilburg. Consenting patients received the questionnaire from the NIVEL research institute. Data of patients with rheumatoid arthritis, ankylosing spondylitis, or arthrosis deformans $(n=336$; response rate $52,5 \%)$ or with asthma, chronic bronchitis or lung emphysema $(n=$ 259 ; response rate $43,1 \%$ ) were included.

Assessment of diagnosis. The diagnoses were established by specialists or GPs. Comorbidity was assessed by means of self-report.

\section{Zutphen Elderly Study}

Context. The Zutphen Elderly study is a longitudinal population-based health study among men born between 1900 and 1920 and living in the town of Zutphen at the start of the study in 1985. Data collected in 1995 were included in the current study. A nonresponse analysis revealed that nonrespondents were older, of a lower socioeconomic class, less frequently living independently, and with a poorer health status in comparison to those who participated.

Sample. Of the 462 surviving patients, 343 (74\%) participated. Data are included of patients with: diabetes mellitus $(\mathrm{n}=38)$; asthma $(\mathrm{n}=26)$; rheumatoid arthritis, osteoarthritis, back impairments $(\mathrm{n}=$ 168); hearing impairments $(n=47)$; visual impairments $(n=34)$; heart disease $(n=78)$; stroke $(n=$ $25)$; cancer $(\mathrm{n}=40)$; and hypertension $(\mathrm{N}=137)$.

Assessment of diagnosis. The diagnoses of diabetes mellitus, asthma, rheumatoid arthritis, osteoarthritis, back impairments, hearing and visual impairments were established via self-report. Stroke and heart disease were determined on the basis of information from the hospital and the GP. The diagnosis cancer was verified with information of the national cancer registries. Hypertension was established with the $\mathrm{WHO}$ definition (i.e., systolis $\geq 160 \mathrm{mmHg}$; diastolis $\geq 90 \mathrm{mmHg}$ and/or use of antihypertension medication). Comorbidity was defined as the presence of two or more endorsed chronic conditions. This implies that respondents may have been included in more than one disease category $[34,35]$.

\section{WOK Project}

Context. Data were collected in the context of the study "Monitoring and feedback regarding asthma and chronic obstructive pulmonary disease (COPD) in the general practice" performed by the Center for Quality of Care Research (WOK) of the research school CaRe, and financed by the Dutch Asthma Foundation. The objective was to evaluate systematic monitoring of patients with asthma or COPD in general practices. The data presented in this article were baseline data collected in 1996.

Sample. Age: 18 years and older, random sample of patients with asthma or COPD from 24 GP practices in the Eastern part of the Netherlands. Exclusion criteria included: a) being under active treatment of a specialist; and b) having serious comorbidities. Patients were approached by their GPs, $647(70 \%)$ consented. The majority of these patients $(70 \%)$ had light or moderate forms of asthma or COPD.

Assessment of diagnosis. The diagnosis was established on the basis of lung function and the prevalence of symptoms. Comorbidity was assessed by means of a self-report list including 18 conditions.

\section{NEMESIS Project}

Context. Data were collected in the context of the Netherlands Mental Health Survey and Incidence Study (NEMESIS) a prospective, ongoing study into the prevalence, incidence, course, and outcome of psychiatric conditions in the Netherlands. Baseline data collected in 1996 were used in the current article [37]. Nonresponse was found to be associated with better mental health, gender (more females), and age (more individuals in the lower age ranges). Psychiatric morbidity did not differ significantly between respondents and nonrespondents. 
Sprangers, M.A.G., Regt, E.B. de, Andries, F., Agt, H.M.E. van, Bijl, R.V., Boer, J.B. de,

Foets, M., Hoeymans, N., Jacobs, A.E., Kempen, G.I.J.M., Miedema, H.S., Tijhuis,

M.A.R., Haes, H.C.J.M. de

Which chronic conditions are associated with better or poorer quality of life?

Journal of Clinical Epidemiology: 53, 2000, nr. 9, p. p. 895-907

Sample. Age: 18-64 years, representative sample of the general population of the Netherlands; 7147 persons $(69.7 \%$ response) were included. Only data of respondents with anxiety disorders $(n=915)$, depression $(n=572)$, and alcohol abuse/dependence $(n=491)$ were used.

Assessment of diagnosis. Diagnoses were established by trained interviewers, using the Composite International Diagnostic Interview (CIDI), according to the criteria of the DSMIII-R. Comorbidity was noted if at least one additional psychiatric disorder was present and/or a chronic condition was endorsed in the self-report list as used by the Central Office for Statistics in the Netherlands.

\section{GLAS Study}

Context. The Groningen Longitudinal Aging Study is a population-based prospective study of the determinants of the QL of late-middle-aged or older people who live in the Northern part of the Netherlands. Baseline data collected in 1993 were included in the current study. Nonresponse was found to be associated with gender (fewer females), age (fewer individuals in the higher age range), and the presence of malignancies.

Sample. Age: 57 years or older, 8723 individuals were approached by their GPs, $62,5 \%$ consented. Data are included of patients with: asthma/chronic bronchitis $(\mathrm{n}=610)$; other lung diseases, such as emphysema $(n=193)$; heart condition $(n=974)$; hypertension $(n=1238)$; stroke $(n=159)$; ulcer in the stomach/duodenum or serious bowel conditions $(n=305)$; liver disease/gallstones or gall bladder inflammation $(n=137)$; renal disease $(n=137)$; non-malignant prostate disease $(n=210)$; diabetes mellitus $(\mathrm{n}=379)$; thyroid gland impairments $(\mathrm{n}=187)$; back problems $(\mathrm{n}=903)$; rheumatoid arthritis/osteoarthritis/other joint complaints $(n=1195)$; migraine/chronic headache $(n=489)$; eczema/psoriasis $(\mathrm{n}=386)$; cancer $(\mathrm{n}=182)$; multiple sclerosis $(\mathrm{n}=12)$; and Parkinson's disease/epilepsy $(\mathrm{n}=89)$.

Assessment of diagnosis. A self-report checklist of 19 chronic medical conditions as employed by the Central Office for Statistics in the Netherlands, was employed. Comorbidity was defined as the presence of two or more endorsed chronic conditions. This implies that respondents may have been included in more than one disease category [32]. 